TITLE:

\title{
Simultaneous Phenomenon of Particle Deposition and Reentrainment: Effects of Surface Roughness on Deposition Layer of Striped Pattern
}

\section{$\operatorname{AUTHOR(S):~}$}

Adhiwidjaja, Indra; Matsusaka, Shuji; Tanaka, Hiroshi; Masuda, Hiroaki

\section{CITATION:}

Adhiwidjaja, Indra ... [et al]. Simultaneous Phenomenon of Particle Deposition and Reentrainment: Effects of Surface Roughness on Deposition Layer of Striped Pattern. Aerosol Science and Technology 2000, 33(4): 323-333

\section{ISSUE DATE:}

2000-10

URL:

http://hdl.handle.net/2433/198911

\section{RIGHT:}

This is an Accepted Manuscript of an article published by Taylor \& Francis in "Aerosol Science and Technology" on 30 Nov 2010, available online: http://www.tandfonline.com/10.1080/02786820050121521.; この論文は出版社版でありませ ん。引用の際には出版社版をご確認じ利用ください。; This is not the published version. Please cite only the published version. 


\section{Simultaneous Phenomenon of Particle Deposition and Reentrainment: Effects of surface roughness on deposition layer of striped pattern}

\section{Indra Adhiwidjaja, Shuji Matsusaka, Hiroshi Tanaka and Hiroaki Masuda}

Department of Chemical Engineering, Kyoto University, Yoshida-honmachi, Sakyo-ku, Kyoto 606-8501, Japan

\section{ABSTRACT.}

Formation of particle deposition layers on rough wall surfaces was studied as a simultaneous phenomenon of particle deposition and reentrainment. The test powders used were alumina of micron sizes and the experiments were conducted under turbulent aerosol flows. After particle deposition and reentrainment reached an equilibrium state, deposition layer of a striped pattern was formed. The striped pattern was characterized by the interval and the thickness, which decreased with increasing the roughness of wall surface. Further, the striped deposition layers moved slowly downstream, and the velocity of the moving deposition layers decreased with increasing the surface roughness. A moment balance model was used to explain the effect of the surface roughness on the velocity of the moving deposition layers.

\section{INTRODUCTION}

In the handling of an aerosol flow, suspended particles are transported toward a wall surface of the equipment or pipes as a result of diffusion, particle inertia, and external forces. The primary particles adhering to the wall surface are difficult to reentrain since the drag force acting on the particle is usually quite weak. Therefore, aerosol particles accumulate on the wall surface and form a particle deposition layer. The drag force acting on the layer increases with the amount of deposited particles and small aggregates will be reentrained readily from the layer (Ikumi et al., 1986). Further, the aerosol particles colliding with the layer enhances the particle reentrainment.

Both particle deposition and reentrainment are fundamental phenomena relating to almost all aerosol operations such as particle generation, powder dispersion, particle size classification, dust collection, and many others. The studies on particle deposition (Papavergos and Hedley, 1984) and reentrainment (Ziskind et al., 1995; Masuda and Matsusaka, 1997) have been carried out from different standpoints. However, these 
phenomena usually occur simultaneously. Several attempts to combine reentrainment and deposition were made (Cleaver and Yates, 1976; Reeks and Hall, 1988), but they did not take account of a real state that aggregates were reentrained from a particle deposition layer.

We have studied the deposition layers formed in a glass tube as a simultaneous phenomenon of particle deposition and reentrainment, showing the following features (Matsusaka et al., 1993; Adhiwidjaja et al., 1996; 1997). Small agglomerates formed on the wall surface, grow and combine neighboring agglomerates, and finally change into striped deposition layers. In this process, it is worth noting that the deposition layers do not grow at the same place but move slowly downstream at a certain constant velocity. The velocity of the moving deposition layer is proportional to the flux of particles colliding with the deposition layer, and the physical significance of the relation was clarified (Adhiwidjaja et al., 1996; 1997). Further, the effects of air velocity and particle diameter on the thickness and the interval of the striped deposition layers were studied experimentally (Matsusaka et al., 1998).

All the above experiments were carried out on smooth surface walls, but in industrial aerosol processes, the surface is not always smooth. In the present paper, we give attention to the striped deposition layers formed on rough surfaces, and discuss the effect of the surface roughness on the movement of the striped deposition layers using a moment balance model for an aggregate on rough surfaces.

\section{MECHANISM OF DEPOSITION LAYER MOVEMENT}

Figure 1 shows the mechanism of the movement of striped deposition layer. The powder layer is formed by the deposition of primary particles onto a wall surface. The particle collision and the drag force make to reentrain small aggregates on the front part of the deposition layer, while particle deposition on the back part forms a new deposition layer. As a result, the particle deposition layer moves downstream; there is no slip of the deposition layer on the wall surface. Namely, the particle collision and the deposition directly control the movement of the deposition layer. To simplify the comprehensive phenomenon, we suppose that the collision flux is equal to the particle deposition flux since these fluxes have the same physical meaning that particles move to the wall surface (Adhiwidjaja et al., 1996). Particle deposition flux $J_{\mathrm{d}}$ is defined by 


$$
J_{\mathrm{d}}=C V \mathrm{~d},
$$

where $c$ is the aerosol concentration and $v_{\mathrm{d}}$ is the particle deposition velocity, which is given by

$$
V \mathrm{~d}=V_{\mathrm{d}}^{+} u^{*},
$$

where $\mathrm{Vd}^{+}$is the dimensionless particle deposition velocity and $u^{*}$ is the friction velocity. Here, $\mathrm{Vd}_{\mathrm{d}}^{+}$is determined by the following experimental equation (Papavergos and Hedley, 1984):

$$
V_{\mathrm{d}}^{+}=k_{1}\left(\tau_{\mathrm{p}}^{+}\right)^{2} \quad\left(0.2<\tau_{\mathrm{p}}{ }^{+}<20\right) .
$$

The dimensionless particle relaxation time $\tau_{\mathrm{p}}{ }^{+}$is given by

$$
\tau_{\mathrm{p}}^{+}=\frac{\rho_{\mathrm{p}} D_{\mathrm{p}}^{2} u^{*^{2}} C_{\mathrm{m}}}{18 \rho_{\mathrm{f}} v_{\mathrm{f}}^{2}},
$$

where $\rho_{\mathrm{p}}$ is the particle density, $D_{\mathrm{p}}$ is the particle diameter, $C_{\mathrm{m}}$ is the Cunningham's slip correction factor, $\rho_{\mathrm{f}}$ is the air density, and $v_{\mathrm{f}}$ is the kinematic viscosity. The near-wall flow is especially important for particle deposition and reentrainment. The friction velocity $u^{*}$ characterizing the wall shear flow can be calculated using the following empirical equation $\left(R e=3 \times 10^{3}-10^{5}\right)$ :

$$
u^{*}=0.199\left(v_{\mathrm{f}} / D_{\mathrm{e}}\right)^{1 / 8} \bar{u}^{7 / 8},
$$

where $D_{\text {e }}$ is the hydraulic diameter of a channel and $\bar{u}$ is the average air velocity. From Eqs. 1-5, particle deposition flux $J_{\mathrm{d}}$ is rewritten as follows:

$$
J_{\mathrm{d}}=k_{2} C^{3} \bar{u}^{35 / 8} \text {. }
$$

When the particle reentrainment relating to the movement of the deposition layer is caused by the particle collision (see Fig. 1), the velocity of the moving deposition layer will be proportional to the particle collision flux. By treating the collision flux approximately equal to the particle deposition flux, the following simple equation is derived. 


$$
\bar{V}_{\mathrm{ag}} \approx k_{3} J_{\mathrm{d}} .
$$

This relation was verified experimentally (Adhiwidjaja et al., 1996; 1997) and found to be adequate. Thus, the movement of striped deposition layer can be characterized by a constant $k_{3}$ in Eq. 7.

\section{EXPERIMENTAL APPARATUS AND PROCEDURE}

Figure 2 shows a schematic diagram of the experimental apparatus. The test powders used in the experiments are alumina $\left(\rho_{\mathrm{p}}=4.0 \times 10^{3} \mathrm{~kg} \mathrm{~m}^{-3}\right)$. The values of the mass median diameter and the geometric standard deviation are listed in Table 1. The powder discharged from a table feeder (Sankyo Piotech MFOV-1) was dispersed into an airflow through an ejector (Japan Pisco VHH 12-801 J). The aerosol concentration was in a range of $0.055-0.065 \mathrm{~kg} \mathrm{~m}^{-3}$, and the experiments were conducted under the Reynolds number, $R e=3 \times 10^{3}-6 \times 10^{3}$ and the dimensionless particle relaxation time, $\tau_{\mathrm{p}}^{+}=15-20$.

The test section consists of a horizontal rectangular channel (10 mm wide, $3 \mathrm{~mm}$ high, and $400 \mathrm{~mm}$ long) made of brass with a glass window on the top. A removable test piece $10 \mathrm{~mm}$ wide and $100 \mathrm{~mm}$ long was installed behind a $300 \mathrm{~mm}$ fore-flow region at the same level as that of the inner wall surface of the channel, and metal parts were grounded to prevent electric charge caused by particle-wall contact electrification from accumulating in the experimental apparatus. The test pieces were made of four different kinds of metal and the surfaces were mechanically treated to vary the surface roughness. The values of the center line average roughness $R_{a}$ measured by a surface profile micrometer (Keyence VF-7500) are listed in Table 2. The particle deposition layers formed on the test pieces were observed through a video microscope (Olympus OVM $1000 \mathrm{~N}$ ) with a zoom lens in the range of 15-120 and the video pictures were analyzed by a computer. The observation area was $5 \mathrm{~mm}$ wide and $50 \mathrm{~mm}$ long at the center of the test pieces.

The powders were dried at $110{ }^{\circ} \mathrm{C}$ for $12 \mathrm{~h}$ and cooled down at room temperature in a desiccator before the experiments. The relative humidity of the airflow was kept at $10 \%$ by a dryer.

\section{EXPERIMENTAL RESULTS AND DISCUSSION}




\section{Observation of striped deposition layers}

Figure 3 shows a typical series of the formation of striped deposition layers on a smooth surface in a rectangular channel. In these photographs, the deposited particles look white and the flow direction of aerosol particles is from left to right. At the beginning of the experiment, spotted agglomerates were formed and they grew oblique-backwards after $25 \mathrm{~s}$. The striped deposition layers were partly formed after $60 \mathrm{~s}$. The remained small agglomerates gradually disappeared with time elapsed and after $180 \mathrm{~s}$ the striped deposition layers were completely formed. Although the state of the deposition layers depends on the conditions of aerosol flow such as particle diameter, air velocity, and aerosol concentration, there were no effects of test piece-materials as long as they were made of conductive metal. Also, preliminary experiments confirmed that the striped pattern was commonly formed irrespective of the shape of the channel (circular or rectangular) and the direction of the channel (horizontal or vertical).

\section{Time-course of deposited particle amount}

Figure 4 shows the variation of the mass of deposited particles per unit area W/A with time elapsed. The value of W/A increases immediately at the beginning of the experiment and becomes constant in a few minutes. The time agrees with that required for the formation of striped deposition layers, which means that the particle deposition and the reentrainment reach an equilibrium state. The constant value $W^{*} / A$ depends on the conditions of aerosol flow.

The mass of particles deposited per unit area and unit time $d(W / A) / d t$ is represented by

$$
\frac{\mathrm{d}(W / A)}{\mathrm{d} t}=J_{\mathrm{d}}-J_{\mathrm{r}}
$$

where $J_{\mathrm{d}}$ is the deposition flux and $J_{\mathrm{r}}$ is the reentrainment flux. On the assumption that the difference between the real and the equilibrium mass of deposited particles control the variation rate of the mass, we adopted a simple equilibrium equation (Matsusaka, et al. 1998); namely,

$$
\frac{\mathrm{d}(W / A)}{\mathrm{d} t}=\frac{1}{\tau}\left(\frac{W^{*}}{A}-\frac{W}{A}\right),
$$


where $\tau$ is a time constant. From Eq. 9, the following equation is derived as follows:

$$
\frac{W}{A}=\frac{W^{*}}{A}\left\{1-\exp \left(-\frac{t}{\tau}\right)\right\} .
$$

The values that calculated using Eq. 10 agree well with the experimental ones, as shown in Fig. 4.

\section{Effects of roughness of wall surface on the formation of striped deposition layers}

Test pieces were ground by emery papers of different grain sizes to vary the surface roughness (the centerline average roughness $R_{\mathrm{a}}=0.12-1.75 \mu \mathrm{m}$ ), then the direction of the surface asperities could be arranged freely. Thus, we prepared two types of test pieces, viz., parallel and perpendicular to the flow. Preliminary experiments using the parallel type test pieces show no effects of the roughness on the deposition layer; all the states of the deposition layers are equal to that on a smooth surface. Therefore, we used only the test pieces having roughness perpendicular to the flow in the later experiments.

Figure 5 shows the photographs of striped deposition layers formed on different rough surfaces $\left(R_{\mathrm{a}}=0.12-1.04 \mu \mathrm{m}\right)$. Although deposition layers were formed on all test pieces, the deposition pattern was different. In particular, the striped deposition pattern was not completed on the rough surfaces with $R_{\mathrm{a}}=1.04 \mu \mathrm{m}$.

Figure 6 shows the effect of the surface roughness on the interval between the striped deposition layers. The median value of interval $d_{s 50}$ decreases owing to the surface roughness $R_{\mathrm{a}}$, though $d_{\mathrm{s} 50}$ increases with average air velocity. Figure 7 shows the effect of the surface roughness on the thickness of the deposition layers. The median value of the thickness $\delta_{\mathrm{p} 50}$ also decreases owing to the surface roughness $R_{\mathrm{a}}$. From the experimental results in Figs. 6 and 7, the relationship between the interval $d_{\mathrm{s} 50}$ and the thickness $\delta_{\text {p50 }}$ can be obtained as shown in Fig. 8. The interval increases with the thickness at a constant average air velocity. This is because a striped deposition layer acts as an obstacle to the next downstream striped deposition layer under inertia regime. The facts that the interval increases with air velocity and/or with particle diameter ( $d_{\mathrm{p} 50}=2.6$ and $4.9 \mu \mathrm{m}$, Matsusaka et al., 1998) can also support the significance of the particle inertia. 


\section{Effect of roughness of wall surface on the velocity of moving deposition layers}

Figure 9 shows the velocity of striped deposition layers $\bar{V}_{\text {ag. }}$ The velocity decreases with increasing surface roughness and becomes quite small or zero over a critical roughness $\left(0.77<R_{\mathrm{a}} *<1.04 \mu \mathrm{m}\right.$ for $\left.D_{\mathrm{p} 50}=3.5 \mu \mathrm{m}\right)$. In addition, experimental study using larger particles showed that the critical roughness increased with the particle diameter $\left(1.04<R_{\mathrm{a}} *<1.75 \mu \mathrm{m}\right.$ for $\left.D_{\mathrm{p} 50}=5.6 \mu \mathrm{m}\right)$. These experimental results imply that the geometrical matter of surface asperities controls the probability of the particle reentrainment.

Next, we discuss the velocity of moving deposition layers $\bar{v}_{\text {ag }}$ as a function of the particle deposition flux $J_{\mathrm{d}}$ (refer to the section of the mechanism of deposition layer movement). The values of the flux $J_{\mathrm{d}}$ can be calculated using Eq. 6. Figure 10 shows the relationship between $\bar{v}_{\text {ag }}$ and $J_{\mathrm{d}}$ with the wall surface roughness $R_{\mathrm{a}}$ as a parameter. The velocity $\bar{v}_{\text {ag }}$ is approximately proportional to the deposition flux $J_{\mathrm{d}}$ and these experimental results agree with the relation represented by Eq. 7. Here, it is of interest that the proportional constant $k_{3}$ tends to decrease with increasing surface roughness.

\section{Moment balance of separation and adhesion}

To analyze the effect of surface roughness on the movement of deposition layer, we apply a moment balance. Since the reentrained particles are not primary particles but small aggregates, we pay attention to a small aggregate on a rough wall surface and neglect the effect of surrounding particles. The situation of the aggregate is shown schematically in Fig. 11, and the followings are assumed; (i) a spherical small aggregate of diameter $D_{\text {ag }}$ contacts with two surface asperities at angle $\alpha$, (ii) the surface roughness is characterized by the asperity radius $R_{\mathrm{a}}$ and the distance between the asperities $a$ (Ziskind et al., 1997), (iii) shear flow in a viscous sub-layer is uniform irrespective of the aggregate or the surface asperities, and (iv) the reentrainment of the aggregate arises from the collision of an aerosol particle as well as the drag caused by airflow (Adhiwidjaja et al., 1996). The aerosol particle collides with the aggregate at a point defined by angle $\beta$ with an incident angle $\gamma$ (Wang, 1990).

The hydrodynamic drag moment is approximated by (Kousaka et al., 1980; Matsusaka and Masuda, 1996) 


$$
\begin{aligned}
M_{\mathrm{d}} & \approx 24 \tau_{\mathrm{w}} D_{\mathrm{ag}}{ }^{3} \int_{0}^{1} Y^{2} \sqrt{Y(1-Y)} \mathrm{d} Y \\
& =\frac{15 \pi}{16} \tau_{\mathrm{w}} D_{\mathrm{ag}}{ }^{3} .
\end{aligned}
$$

The moment $M_{\mathrm{c}}$ caused by the particle collision is given by

$$
\begin{aligned}
M_{\mathrm{c}} & =\frac{F_{\mathrm{c}} D_{\mathrm{ag}}}{2}\{\cos \gamma(\cos \alpha+\sin \beta)-\sin \gamma(\cos \beta+\sin \alpha)\} \\
& =\frac{F_{\mathrm{c}} D_{\mathrm{ag}}}{2}\{\cos (\alpha+\gamma)+\sin (\beta-\gamma)\},
\end{aligned}
$$

where $F_{\mathrm{c}}$ is the maximum collision force based on Hertz theory, which is given by (Ghadiri, 1997)

$$
F_{\mathrm{C}}=1.12 k^{-2 / 5} m^{3 / 5} D^{1 / 5} V^{6 / 5},
$$

in which $k=\left(1-v_{1}^{2}\right) / E_{1}+\left(1-v_{2}^{2}\right) / E_{2}, m=m_{1} m_{2} /\left(m_{1}+m_{2}\right), D=D_{1} D_{2} /\left(D_{1}+D_{2}\right), v$ is the collision velocity, $v$ is the Poisson's ratio, $E$ is the Young's modulus, $m$ is the mass, $D$ is the diameter, and subscripts 1 and 2 refer to the two colliding bodies (here, aerosol particle and aggregate respectively).

The surface roughness of the test pieces used in the experiments can be characterized by an equation: $a=2.5 R_{\mathrm{a}}$, therefore angle $\alpha$ in Eq. 12 is given by

$$
\alpha=\sin ^{-1}\left(\frac{2.5 R_{\mathrm{a}}}{2 R_{\mathrm{a}}+D_{\mathrm{ag}}}\right) .
$$

The diameter of the aggregate $D_{\text {ag }}$ is estimated about twice as large as that of the primary particle $D_{\mathrm{p}}$ on the basis of the result derived from the experimental data (Adhiwidjaja et al., 1997). Comparing the two moments $M_{\mathrm{c}}$ and $M_{\mathrm{d}}$ in the experimental conditions with the assumption that the two angles $\beta$ and $\gamma$ are equal to zero and the aerosol collision velocity is equal to the airflow at the same height, it was found that $M_{\mathrm{c}}$ is significantly larger than $M_{\mathrm{d}}$. Therefore, we consider $M_{\mathrm{c}}$ as a separation moment on the later analysis.

On the other hand, the adhesion moment $M_{\mathrm{a}}$ is given by

$$
M_{\mathrm{a}}=F_{\mathrm{a}} D_{\mathrm{ag}} \sin \alpha,
$$


where $F_{\mathrm{a}}$ is the adhesive force. Although liquid bridge force, electrostatic force, and van der Waals force act generally on the contact bodies, the liquid bridge force and the electrostatic force can be neglected because of low relative humidity ( $\approx 10 \%$ ) and low particle charge $\left(<1 \mathrm{mC} \mathrm{kg}^{-1}\right)$. The van der Waals force is given by

$$
F_{\mathrm{a}}=\frac{A D}{12 z^{2}}
$$

where $A=\left(A_{1} A_{2}\right)^{1 / 2}, D=D_{1} D_{2} /\left(D_{1}+D_{2}\right), A$ is a Hamaker constant, which can be estimated $A \approx 2 \times 10^{-19} \mathrm{~J}$ (Visser, 1972), $\mathrm{z}$ is the separation gap (=0.4 $\mathrm{nm}$ ), and subscripts 1 and 2 refer to the two contact bodies: primary particle and surface asperity respectively.

From Eqs. 12 and 15, the moment ratio of the particle collision to adhesion is obtained as

$$
\frac{M_{\mathrm{c}}}{M_{\mathrm{a}}}=\frac{\cos (\alpha+\gamma)+\sin (\beta-\gamma)}{2 \sin \alpha} \frac{F_{\mathrm{c}}}{F_{\mathrm{a}}} .
$$

If the moment ratio $M_{\mathrm{c}} / M_{\mathrm{a}}$ is larger than unity, the aggregate will be reentrained and it means that the striped deposition layers move downstream. On the contrary, when the moving striped deposition layers become to stop, $M_{\mathrm{c}} / M_{\mathrm{a}}$ is equal to unity.

Figure 12 shows the relationship between the characteristic value of the moving striped deposition layer $k_{3}$ and the moment ratio $M_{\mathrm{c}} / M_{\mathrm{a}}$. The characteristic value $k_{3}$ $\left(=\bar{V}_{\mathrm{ag}} / J_{\mathrm{d}}\right)$ that is a proportional constant in Eq. 7 increases with $M_{\mathrm{c}} / M_{\mathrm{a}}$. Here, the values of the moment ratio $M_{\mathrm{c}} / M_{\mathrm{a}}$ were calculated with $\beta=\gamma=0$ as a typical condition. Using other values for the geometrical variables, $\alpha, \beta$ and $\gamma$ in Eq. 17, $M_{\mathrm{c}} / M_{\mathrm{a}}$ are varied corresponding to the variables. However, the correlation between $k_{3}$ and $M_{\mathrm{c}} / M_{\mathrm{a}}$ will be still kept as long as the variables are in practical range.

\section{CONCLUSIONS}

The formation of particle deposition layers on rough surfaces were studied theoretically and experimentally using the test powders of micron sizes, and the following conclusions were drawn.

(1) The mass of deposition layers increases with time elapsed in the early stages and it becomes constant as the particle deposition and the reentrainment reach an equilibrium state. Then striped deposition layers are formed. The striped pattern is influenced by 
wall surface roughness. The interval and the thickness of the striped deposition layers decrease with increasing surface roughness at a constant average air velocity. In particular, the striped pattern is not completed if the roughness is larger than a critical value.

(2) The striped deposition layers move slowly downstream at a certain constant velocity as a result of simultaneous particle deposition and reentrainment. The velocity of the moving deposition layers is approximately proportional to the particle deposition flux. The proportional constant decreases with increasing surface roughness. The constant can be characterized by the moment ratio derived by particle collision and adhesion. 


\section{NOMENCLATURE}

A

$a$

Hamaker constant (J)

$C_{\mathrm{m}}$

distance between asperities (m)

C

$D \quad$ diameter $\left(=D_{1} D_{2} /\left(D_{1}+D_{2}\right)\right)$ in Eqs.13,16 (m)

$D_{\text {ag }} \quad$ diameter of an aggregate (m)

$D_{\mathrm{e}} \quad$ hydraulic diameter of a channel (m)

$D_{\mathrm{p}} \quad$ particle diameter (m)

$D_{\text {p50 }} \quad$ mass median diameter of a particle (m)

$d_{\text {s50 }} \quad$ median value of interval between deposition layers (m)

E Young's modulus $\left(\mathrm{N} \mathrm{m}^{-2}\right)$

$F_{\mathrm{a}} \quad$ adhesive force $(\mathrm{N})$

$F_{\mathrm{C}} \quad$ maximum collision force $(\mathrm{N})$

$J_{\mathrm{d}} \quad$ particle deposition flux $\left(\mathrm{kg} \mathrm{m}^{-2} \mathrm{~s}^{-1}\right)$

$J_{\mathrm{r}} \quad$ particle reentrainment flux $\left(\mathrm{kg} \mathrm{m}^{-2} \mathrm{~s}^{-1}\right)$

$k=\left(1-v_{1}^{2}\right) / E_{1}+\left(1-v_{2}^{2}\right) / E_{2} \quad\left(\mathrm{~Pa}^{-1}\right)$

$k_{1} \quad$ constant in Eq.3 (in present experiment, $\left.k_{1}=5.1 \times 10^{-4}\right)(-)$

$k_{2} \quad$ constant in Eq.6 $\left(=\left(9.63 \times 10^{-7}\right) k_{1} C_{\mathrm{m}}{ }^{2}\left(\rho_{\mathrm{p}} / \rho_{\mathrm{f}}\right)^{2} D_{\mathrm{p}}{ }^{4} D_{\mathrm{e}^{-5 / 8}} \mathrm{vf}^{-27 / 8}\right)\left(\mathrm{m}^{-27 / 8}\right.$ $\left.S^{27 / 8}\right)$

k3 constant in Eq.7 $\left(\mathrm{m}^{3} \mathrm{~kg}^{-1}\right)$

$M_{\mathrm{a}} \quad$ moment caused by particle adhesion ( $\mathrm{N} \mathrm{m}$ )

$M_{\mathrm{c}} \quad$ moment caused by particle collision ( $\mathrm{N} \mathrm{m}$ )

$M_{\mathrm{d}} \quad$ hydrodynamic drag moment ( $\left.\mathrm{N} \mathrm{m}\right)$

$m \quad \operatorname{mass}\left(=m_{1} m_{2} /\left(m_{1}+m_{2}\right)\right)(\mathrm{kg})$

$R_{\mathrm{a}} \quad$ center line average roughness (m)

$R_{\mathrm{a}} * \quad$ critical roughness (m)

Re Reynolds number (-)

$t \quad$ time elapsed (s)

$u \quad$ air velocity close to a wall surface $\left(\mathrm{m} \mathrm{s}^{-1}\right)$

$\bar{u} \quad$ average air velocity $\left(\mathrm{m} \mathrm{s}^{-1}\right)$

$u^{*} \quad$ friction velocity $\left(\mathrm{m} \mathrm{s}^{-1}\right)$

$v \quad$ particle collision velocity $\left(\mathrm{m} \mathrm{s}^{-1}\right)$ 


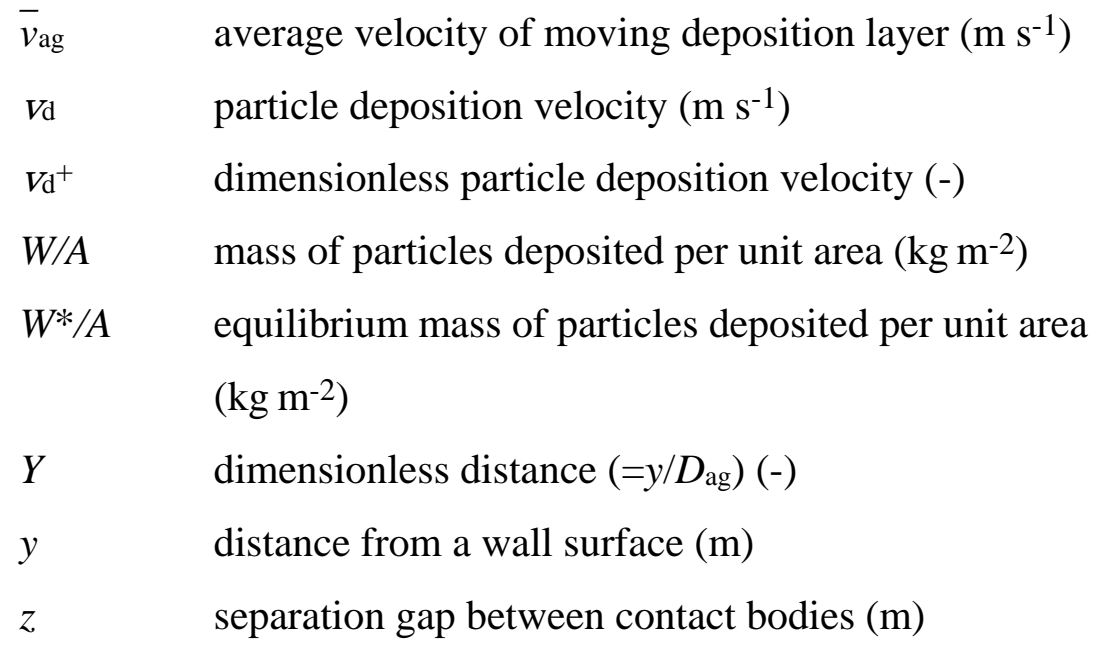

\section{Greek Letters}

$\begin{array}{ll}\alpha & \text { angle in Eq. 12 (rad) } \\ \beta & \text { angle in Eq.12 (rad) } \\ \delta_{\mathrm{p} 50} & \text { median value of layer thickness (m) } \\ \gamma & \text { incident angle in Eq.12 (rad) } \\ v \mathrm{f} & \text { kinematic viscosity of air }\left(\mathrm{m}^{2} \mathrm{~s}^{-1}\right) \\ v & \text { Poisson's ratio (-) } \\ \rho_{\mathrm{f}} & \left.\text { air density (kg } \mathrm{m}^{-3}\right) \\ \rho_{\mathrm{p}} & \left.\text { particle density (kg } \mathrm{m}^{-3}\right) \\ \sigma_{\mathrm{g}} & \text { geometric standard deviation (-) } \\ \tau & \text { time constant (s) } \\ \tau_{\mathrm{p}}{ }^{+} & \text {dimensionless particle relaxation time (-) } \\ \tau_{\mathrm{w}} & \text { wall shear stress (Pa) }\end{array}$




\section{References}

Adhiwidjaja, I., Matsusaka, S. and Masuda, H. (1996). Mechanism of Formation of Particle Deposition Layers by an Aerosol Flow. Kagaku Kogaku Ronbunshu. 22:127-133.

Adhiwidjaja, I., Matsusaka, S., Hamamura, T. and Masuda, H. (1997). The Effect of Particle Size on the Movement of a Striped Pattern Deposition Layer in an Aerosol Flow. J. Soc. Powder Technol. Jpn. 34:913-918.

Cleaver, J. W., and Yates, B. (1976). The Effect of Re-entrainment on Particle Deposition. Chem. Eng. Sci. 31:147-151.

Ghadiri., M. (1997). Particle Impact and Attrition., in Powder Technology Handbook, K. Gotoh, H. Masuda, K. Higashitani, eds. 2nd edn. Marcel Dekker, New York, pp.183-184.

Ikumi, S., Wakayama, H. and Masuda, H. (1986). Particle Reentrainment by an Air Stream from Deposited Layer. Kagaku Kogaku Ronbunshu. 12:589-594.

Kousaka, Y., Okuyama, K. and Endo, Y. (1980). Re-entrainment of Small Aggregate Particles from a Plane Surface by Air Stream. J. Chem. Eng. Jpn. 13:143-147. Masuda, H. and Matsusaka, S. (1997). Particle Deposition and Reentrainment, in Powder Technology Handbook, K. Gotoh, H. Masuda, K. Higashitani, eds. 2nd edn. Marcel Dekker, New York, pp.143-154.

Matsusaka, S., Shimizu, M. and Masuda, H. (1993). Formation of Wall Particle Layers by Simultaneous Deposition and Reentrainment of Fine Particles in Turbulent Aerosol Flows. Kagaku Kogaku Ronbunshu. 19:251-257.

Matsusaka, S. and Masuda, H. (1996). Particle Reentrainment from a Fine Powder Layer in a Turbulent Air Flow. Aerosol Sci. Technol. 24:69-84.

Matsusaka, S., Adhiwidjaja, I., Nishio T. and Masuda, H. (1998). Formation of Striped Pattern Deposition Layers by an Aerosol Flow —Analysis of Thickness and Interval of Layers-. Advanced Powder Technol. 9:207-218

Papavergos, P. G., and Hedley, A. B. (1984). Particle Deposition Behavior from Turbulent Flows. Chem. Eng. Res. Des. 62:275-295.

Reeks, M. W. and Hall, D. (1988). Deposition and Resuspension of Gas-borne Particles in Recirculating Turbulent Flows. J. Fluids Eng. 110:165-171.

Visser, J. (1972). On Hamaker Constants: a Comparison Between Hamaker Constants and Lifshitz-van der Waals Constants. Advan. Colloid Interface Sci. 3:331-363. 
Wang, H-C. (1990). Effects of Inceptive Motion on Particle Detachment from Surfaces. Aerosol Sci. Technol. 13:386-393.

Ziskind, G., Fichman, M. and Gutfinger, C. (1995). Resuspension of Particulates from Surfaces to Turbulent Flows — Review and Analysis—. J. Aerosol Sci. 26:613-644. Ziskind, G., Fichman, M. and Gutfinger, C. (1997). Adhesion Moment Model for Estimating Particle Detachment from a Surface. J. Aerosol Sci. 28:623-634. 
A Self-archived copy in

京都大学

Kyoto University Research Information Repository

KURENAI 就

(i)
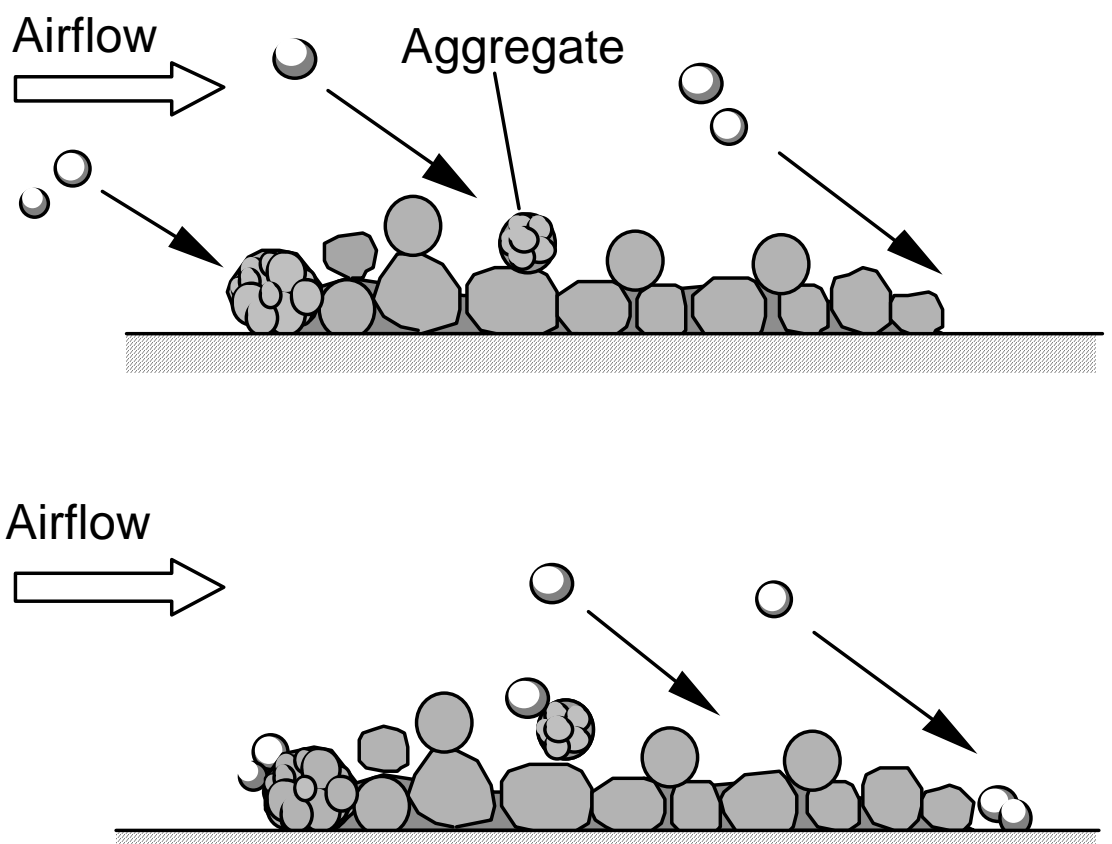

(ii)

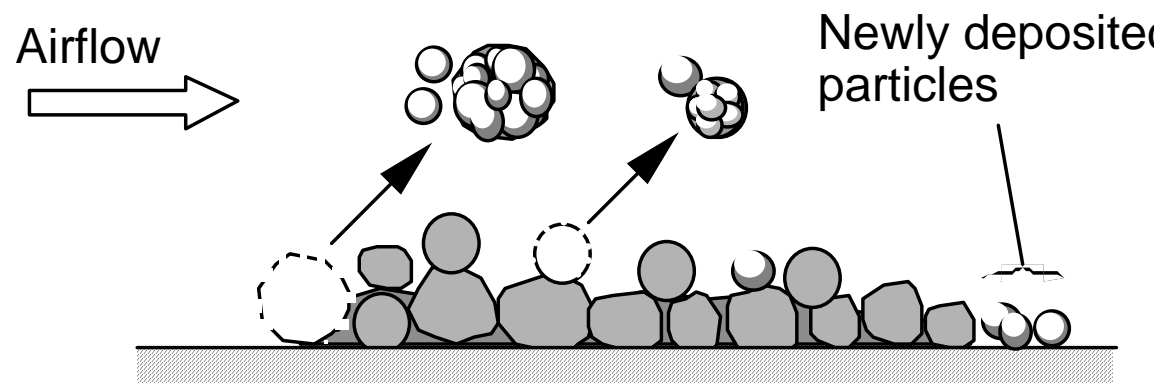

FIGURE 1. Mechanism of striped deposition layer movement (sectional view). 


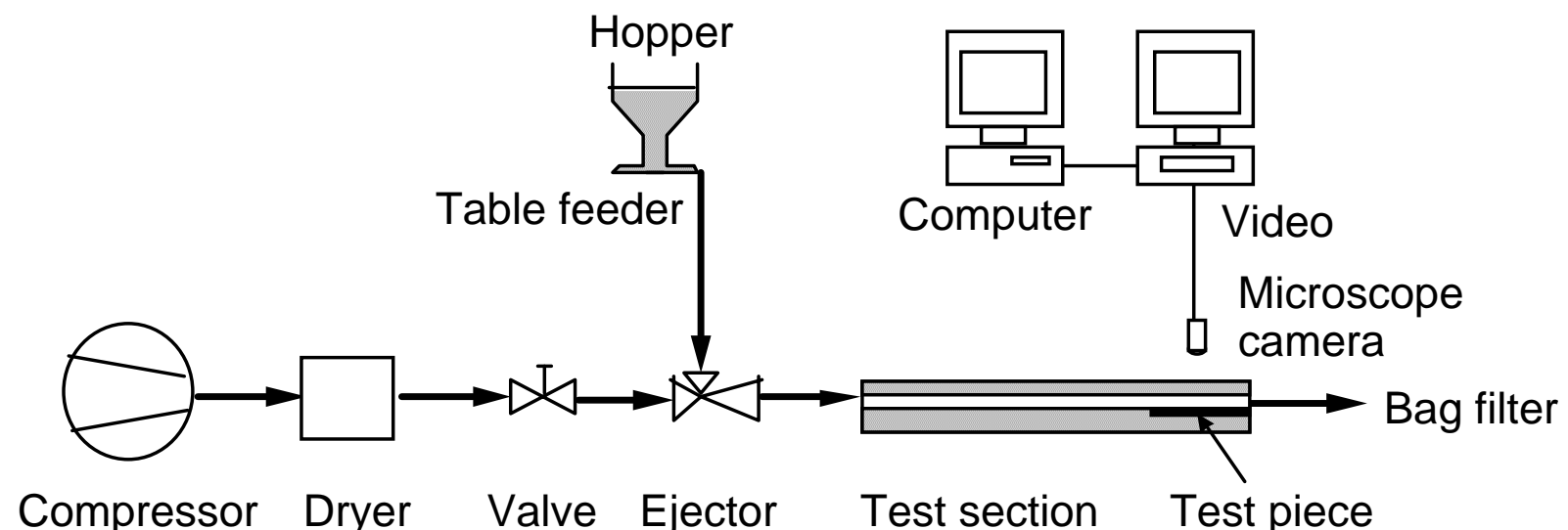

FIGURE 2. Experimental apparatus. 
TABLE 1. Test powders used (Alumina).

\begin{tabular}{cc}
\hline$D_{\mathrm{p} 50}(\mu \mathrm{m})$ & $\sigma_{\mathrm{g}}(-)$ \\
3.5 & 1.44 \\
4.7 & 1.42 \\
5.6 & 1.44 \\
\hline
\end{tabular}


TABLE 2. Wall properties of test pieces.

\begin{tabular}{cc}
\hline Materials & Roughness, $R_{\mathrm{a}}(\mu \mathrm{m})$ \\
& 0.12 \\
& 0.22 \\
& 0.34 \\
Brass & 0.46 \\
& 0.77 \\
& 1.04 \\
& 1.75 \\
$\ldots \ldots \ldots \ldots \ldots \ldots \ldots \ldots$ \\
Copper & 0.09 \\
Aluminium & 0.07 \\
Stainless steel & 0.12 \\
\hline
\end{tabular}



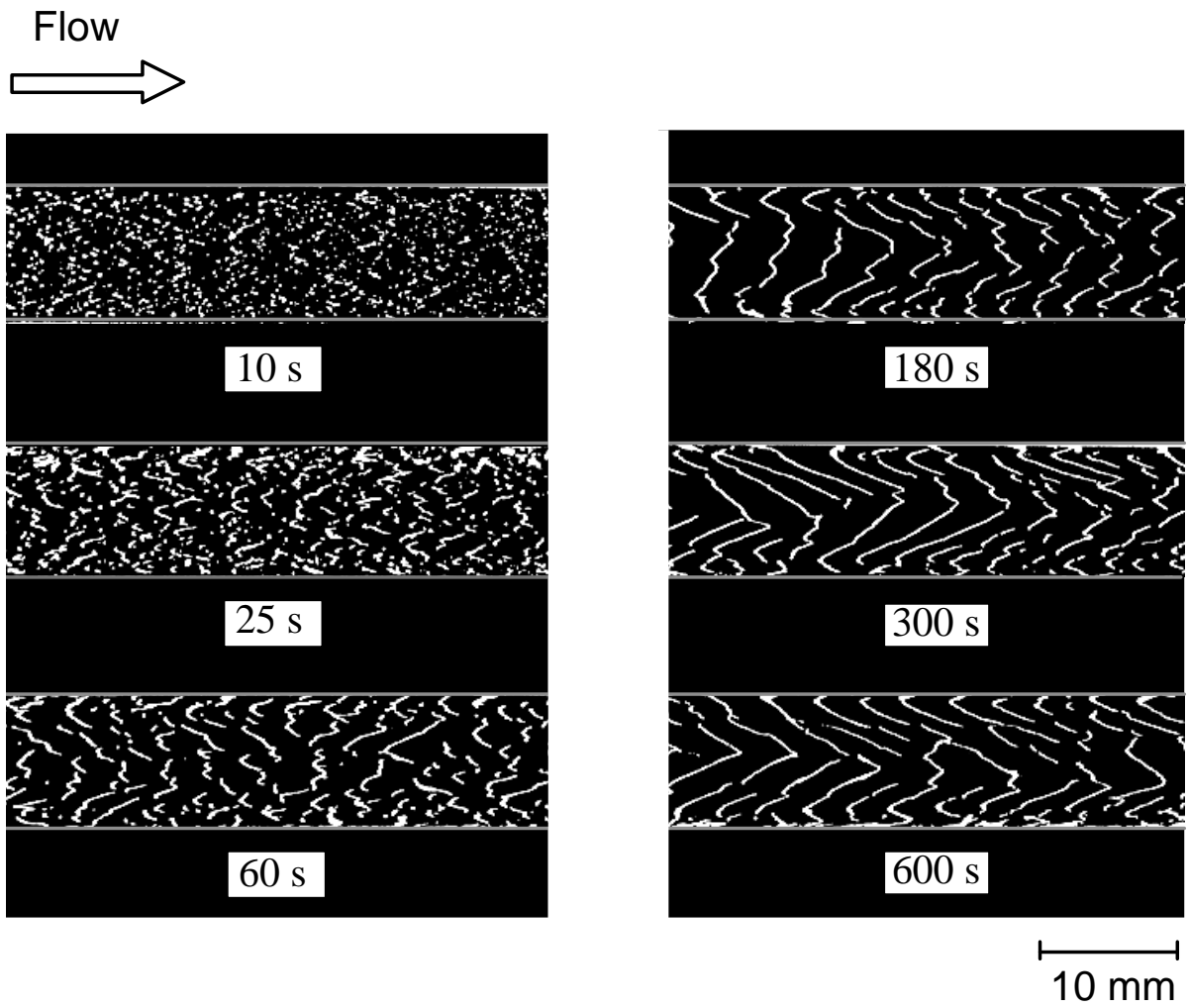

FIGURE 3. Formation of striped deposition layers in a rectangular channel $\left(D_{\mathrm{p} 50}=3.5 \mu \mathrm{m}, \bar{u}=17.2 \mathrm{~m} \cdot \mathrm{s}^{-1}, c=0.058 \mathrm{~kg} \cdot \mathrm{m}^{-3}\right.$, Brass: $\left.R_{\mathrm{a}}=0.12 \mu \mathrm{m}\right)$. 


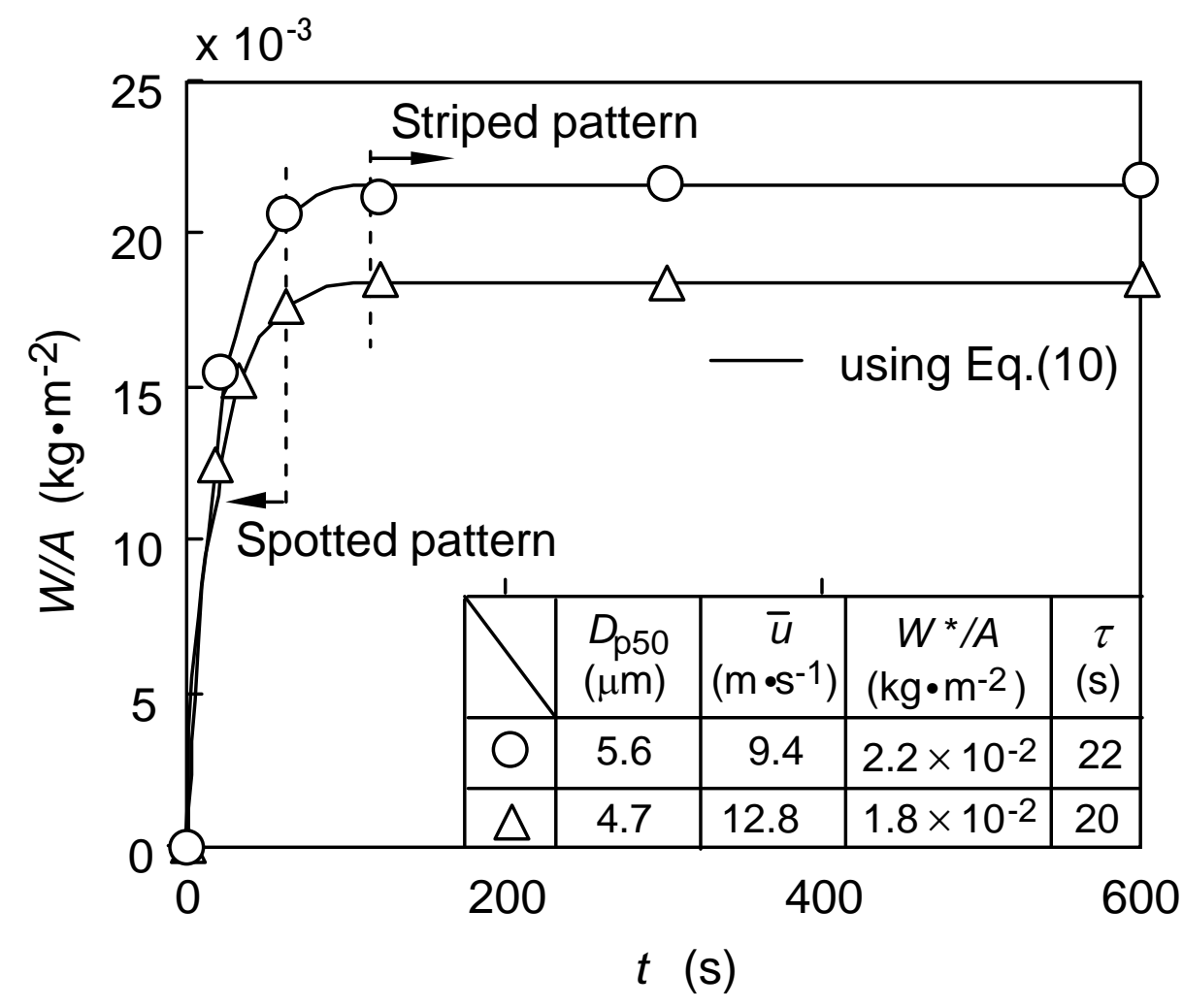

FIGURE 4. The mass of particles deposited per unit area W/A as a function of time elapsed. 


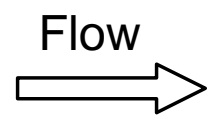

$R_{\mathrm{a}}=0.12 \mu \mathrm{m}$

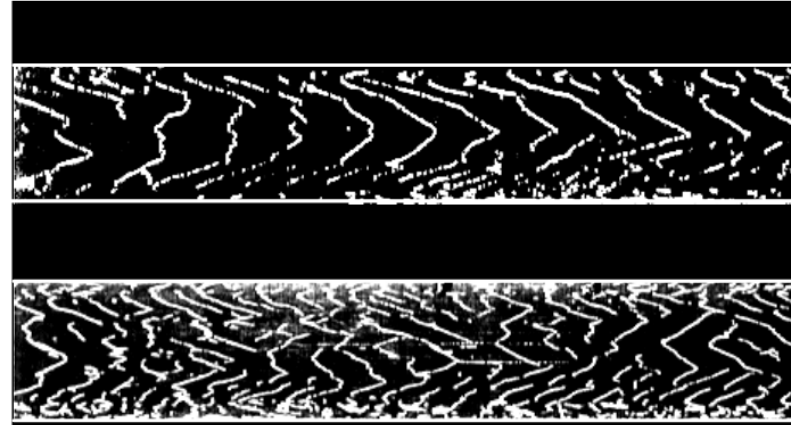

$R_{\mathrm{a}}=0.34 \mu \mathrm{m}$

$R_{\mathrm{a}}=0.22 \mu \mathrm{m}$

$R_{\mathrm{a}}=0.46 \mu \mathrm{m}$

$R_{\mathrm{a}}=0.77 \mu \mathrm{m}$

$R_{\mathrm{a}}=1.04 \mu \mathrm{m}$
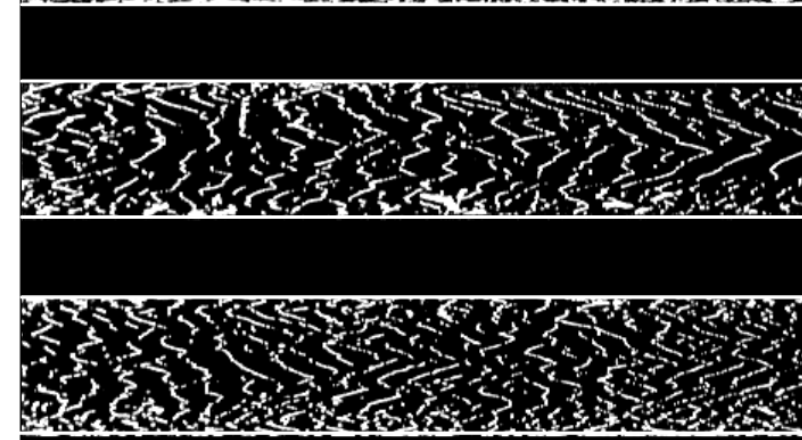

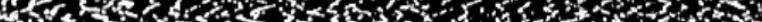

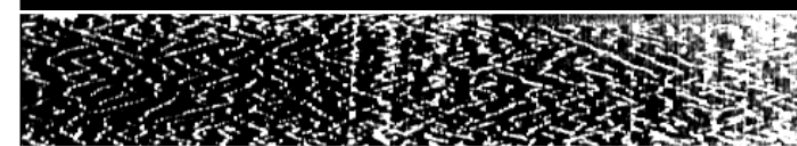

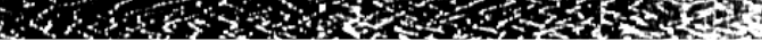

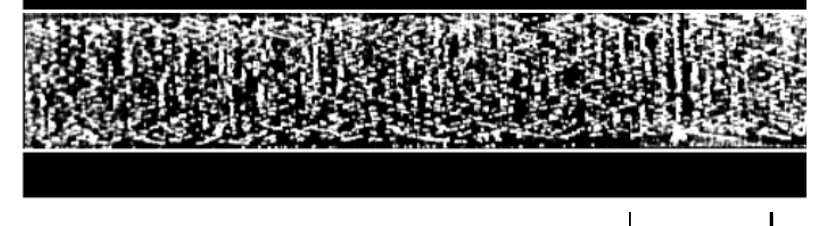

$10 \mathrm{~mm}$

FIGURE 5. Photographs of striped deposition layers formed on different rough surfaces

$$
\left(D_{\mathrm{p} 50}=3.5 \mu \mathrm{m}, \bar{u}=18.2 \mathrm{~m} \cdot \mathrm{s}^{-1}, c=0.055 \mathrm{~kg} \cdot \mathrm{m}^{-3}\right) \text {. }
$$




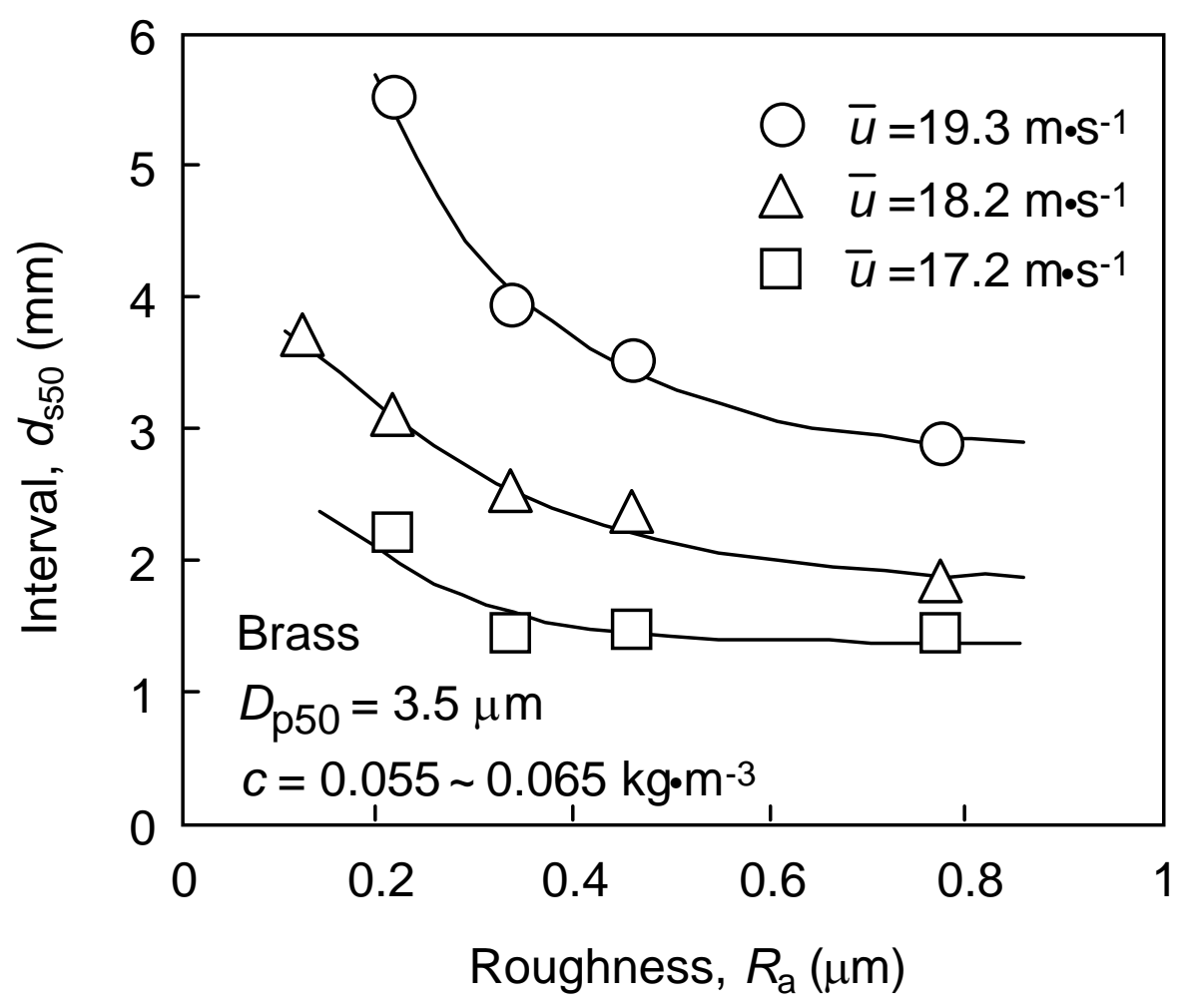

FIGURE 6. Effect of wall surface roughness on interval between striped deposition layers $(t=600 \mathrm{~s})$. 


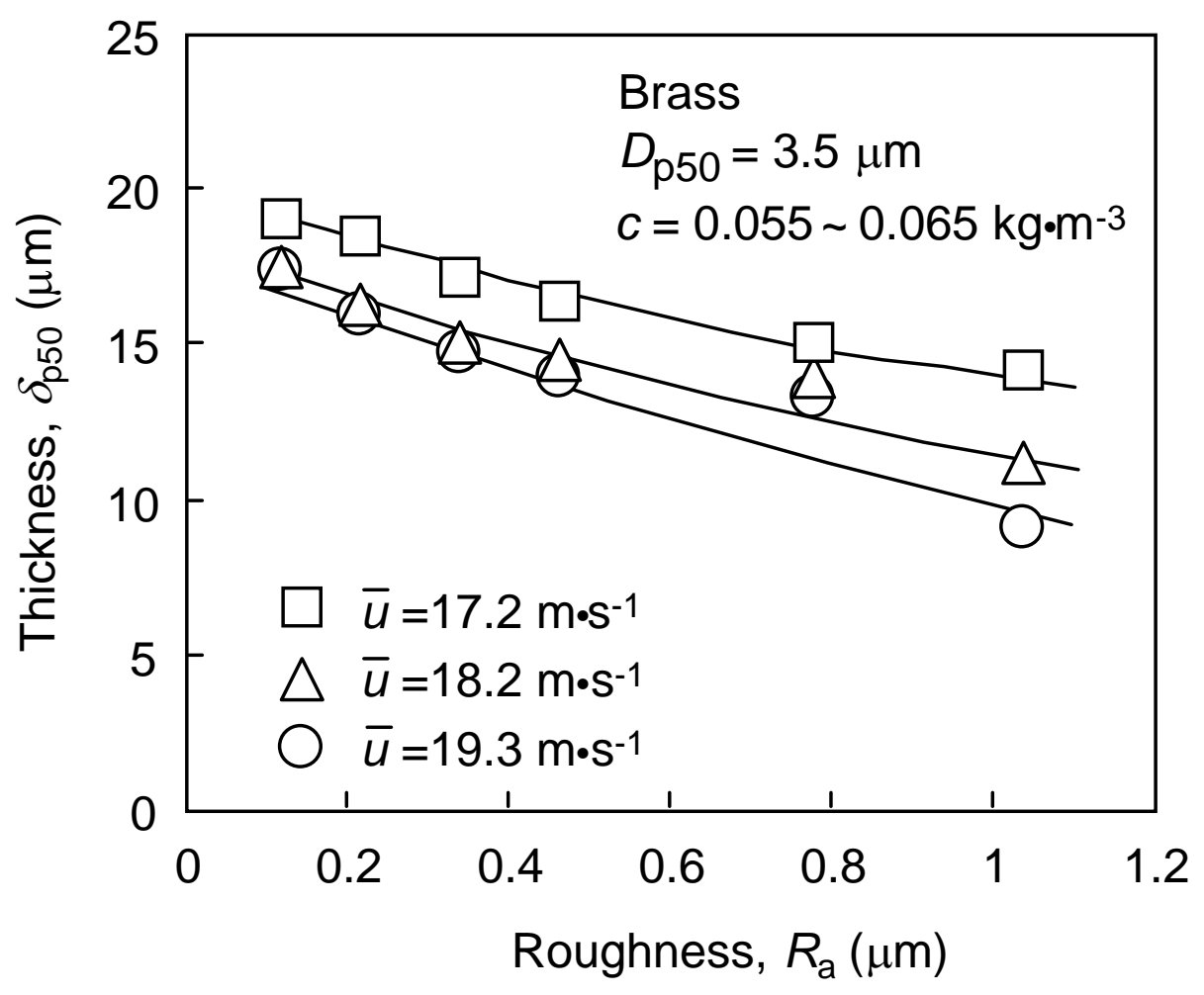

FIGURE 7. Effect of wall surface roughness on thickness of striped deposition layers $(t=600 \mathrm{~s})$. 


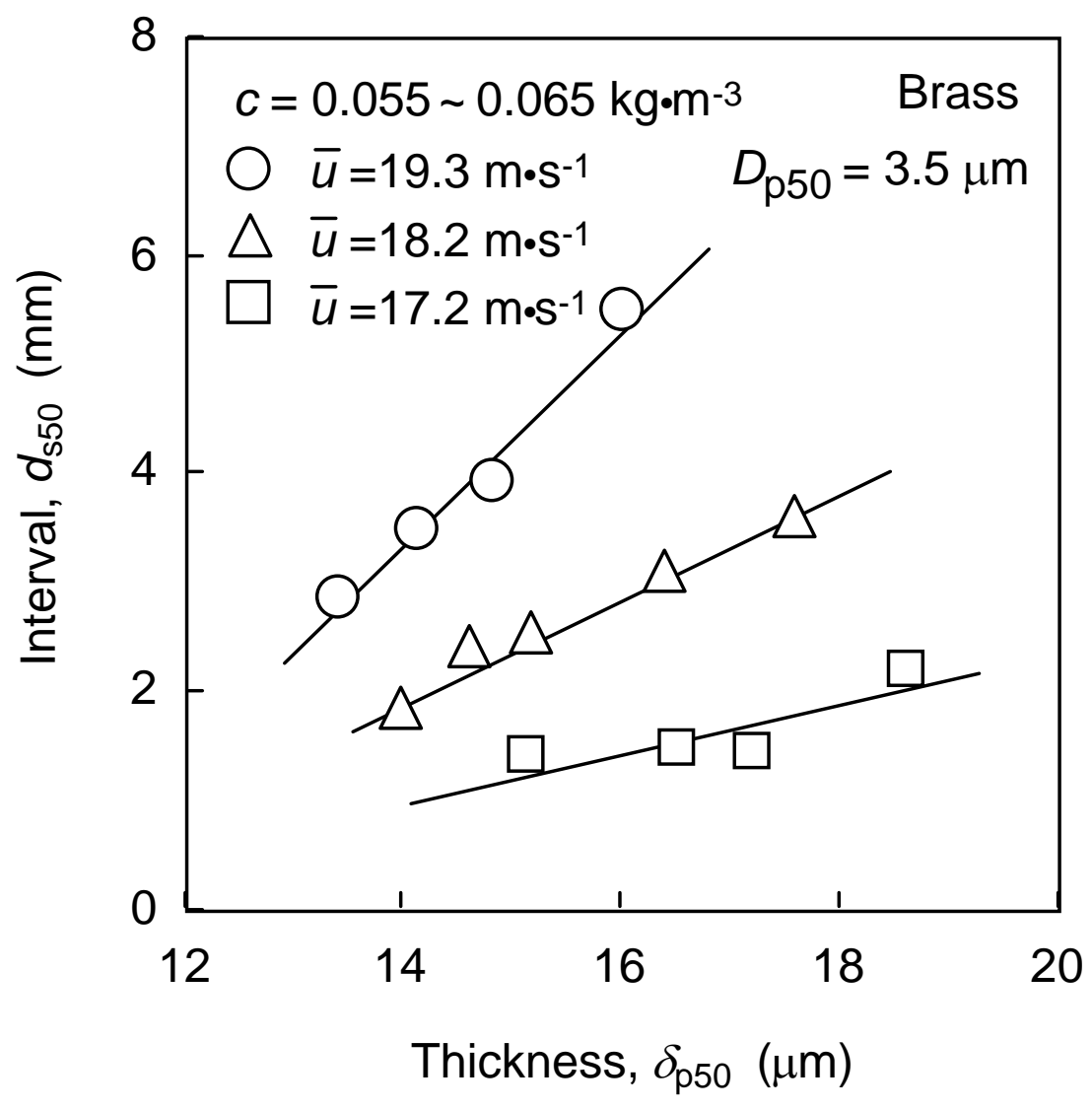

FIGURE 8. Relationship between interval and thickness of striped deposition layers $(t=600 \mathrm{~s})$. 


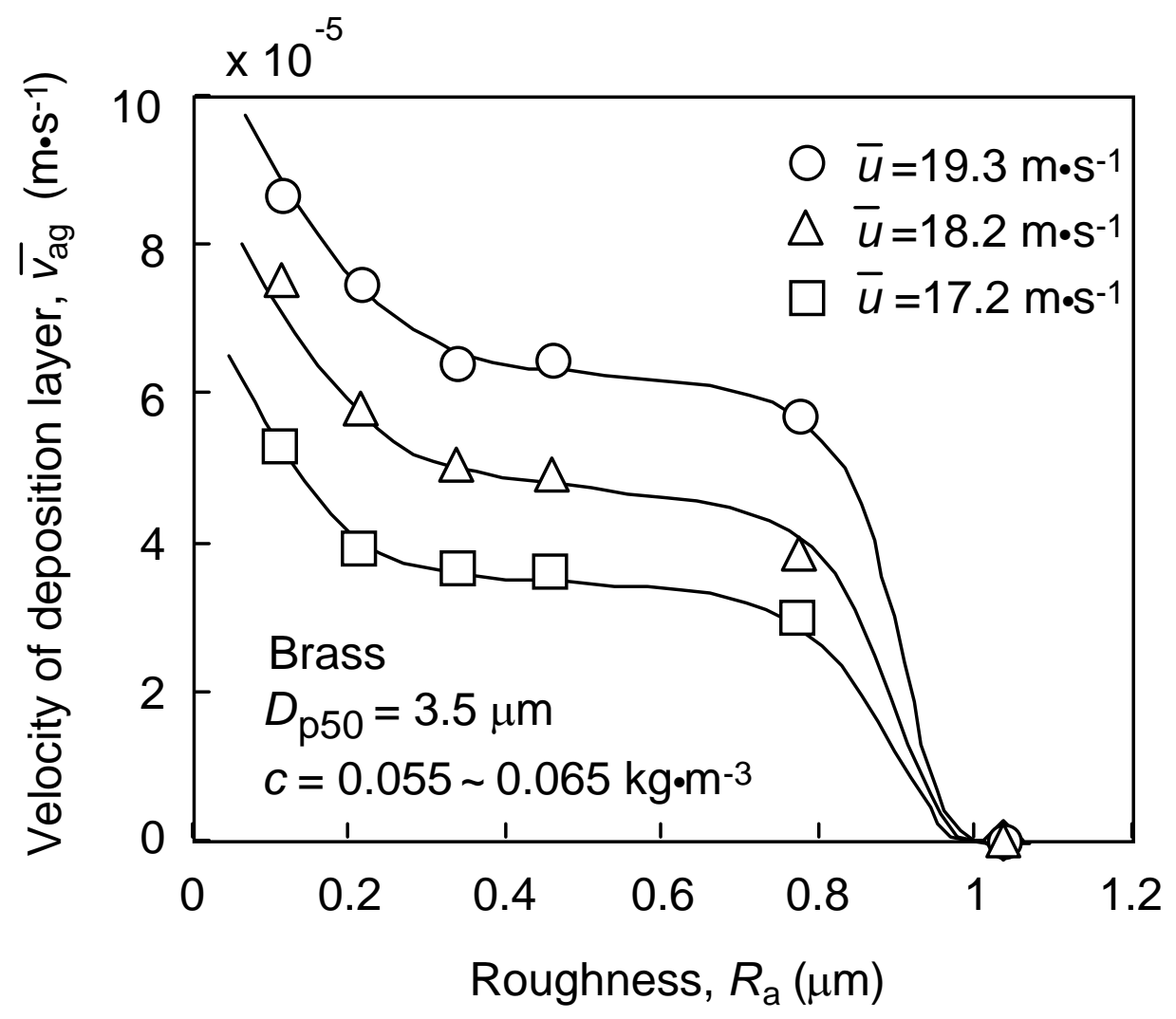

FIGURE 9. Effect of surface roughness on the movement of the striped deposition layers $(t=600 \mathrm{~s})$. 


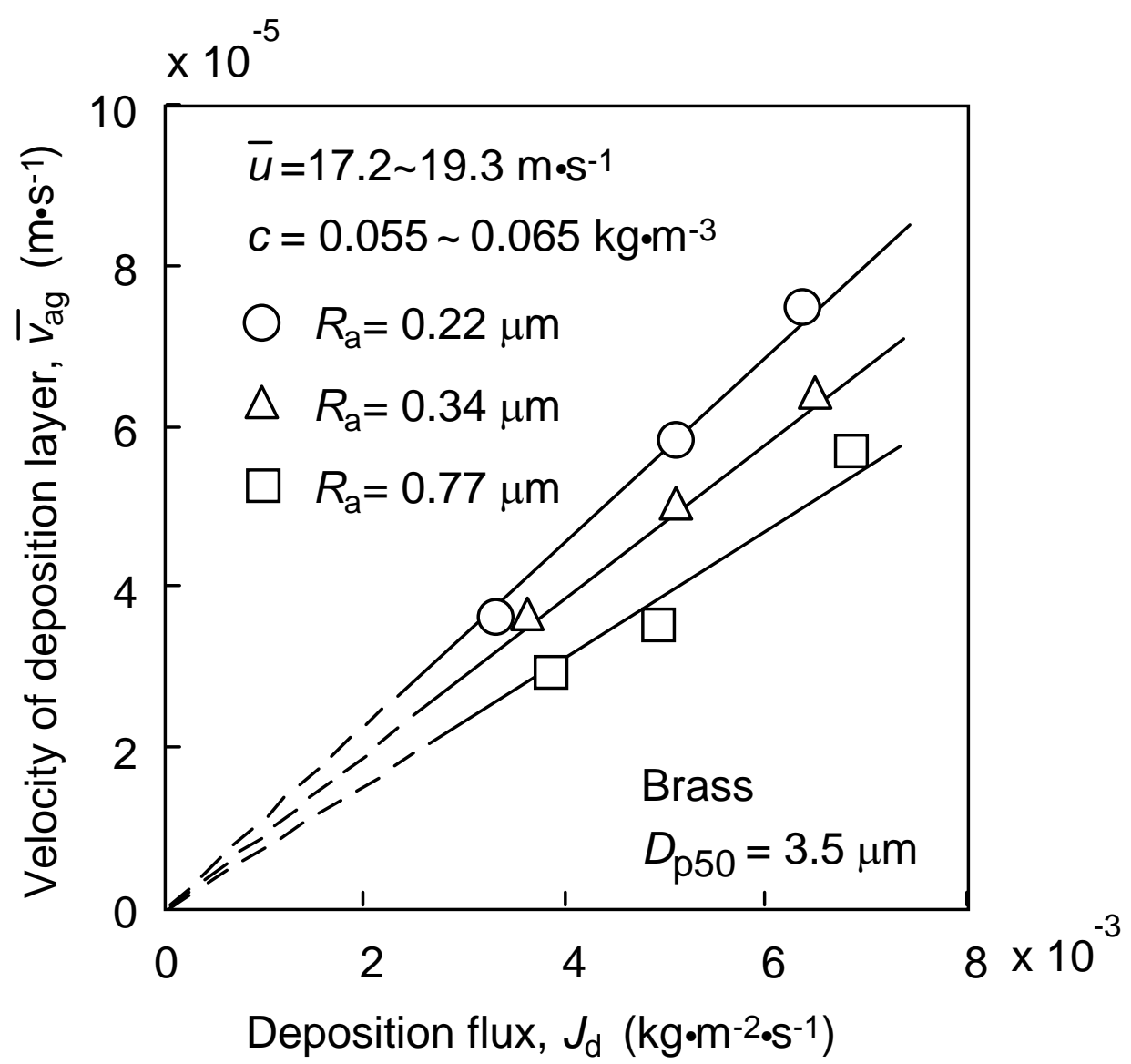

FIGURE 10. Relationship between $\bar{v}_{\mathrm{ag}}$ and $J_{\mathrm{d}}$ with surface roughness as a parameter $(t=600 \mathrm{~s})$. 


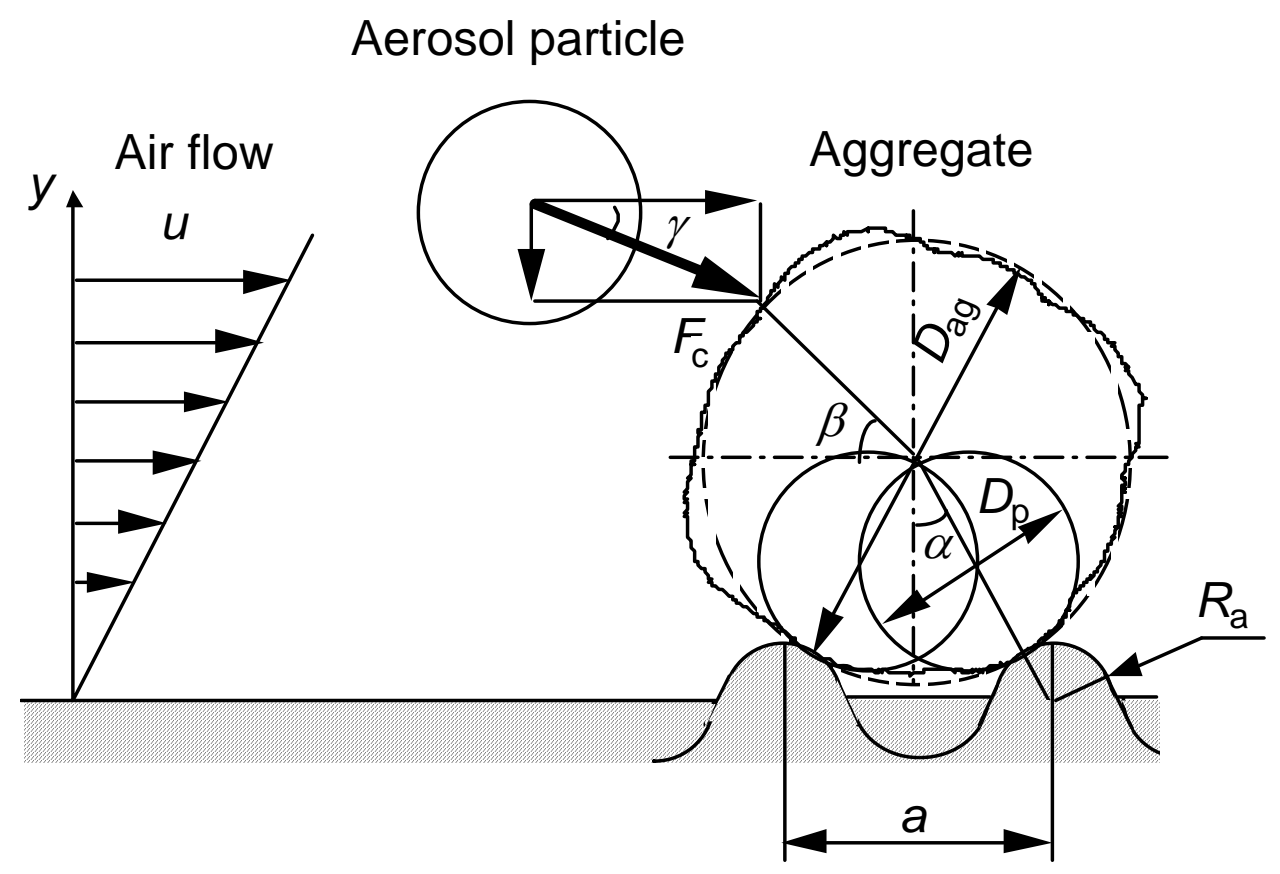

FIGURE 11. Schematic diagram of particle impacting upon an aggregate particle on the rough surface. 


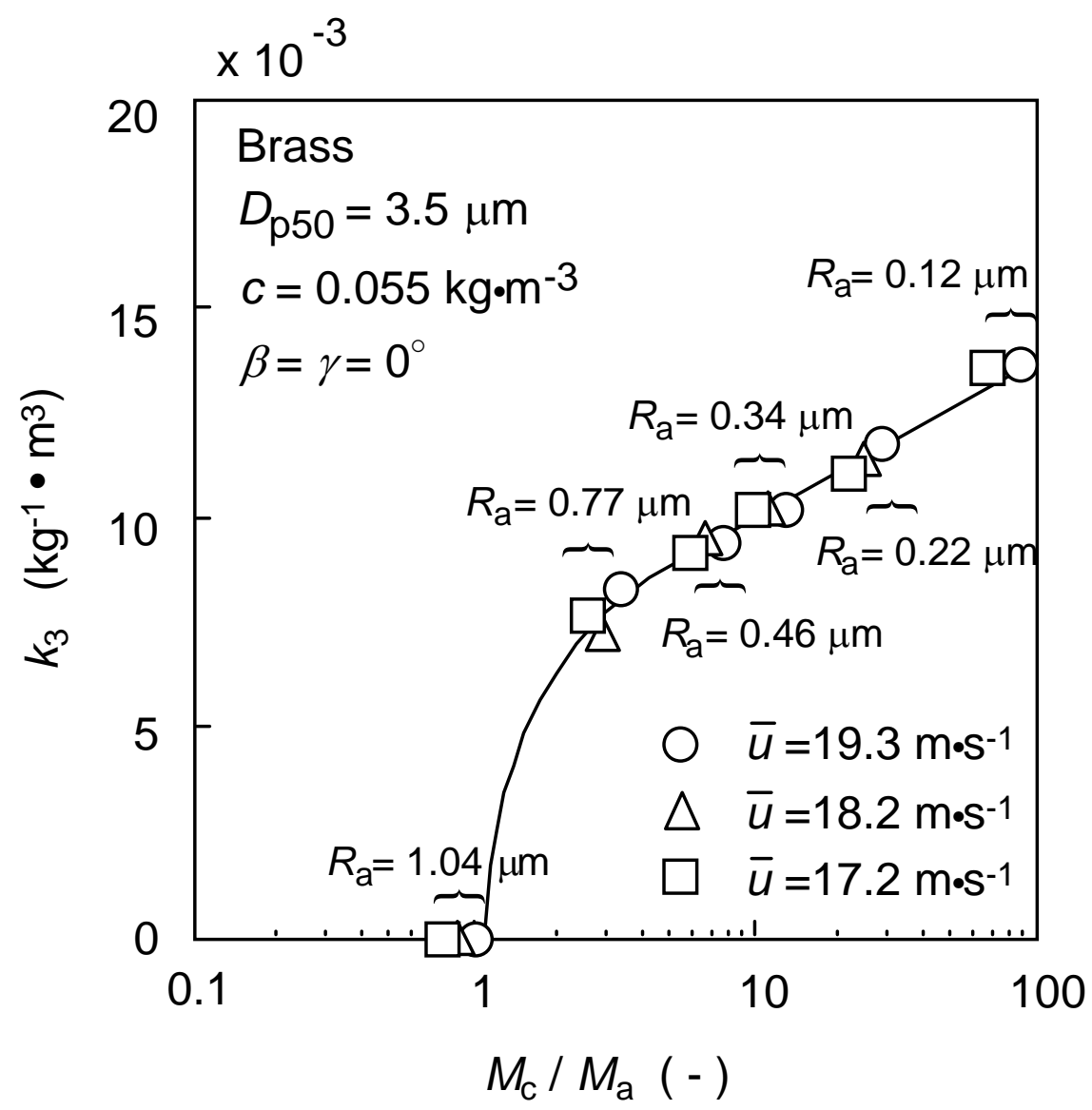

FIGURE 12. Relationship between characteristic value of striped deposition layer movement $k_{3}\left(=\overline{v_{a g}} / J_{d}\right)$ and moment ratio $M_{\mathrm{c}} / M_{\mathrm{a}}$. 